\title{
International Journal of Technology and Systems
}

(IJTS)

\section{AN APPRAISAL OF VIRTUAL INTERNSHIP IN KENYA: EXPERIENCES AND PERCEPTIONS DURING COVID-19 PANDEMIC}

Olayo Julius Ochieng PhD, CHRP-K and Lewis Waithaka Kamau

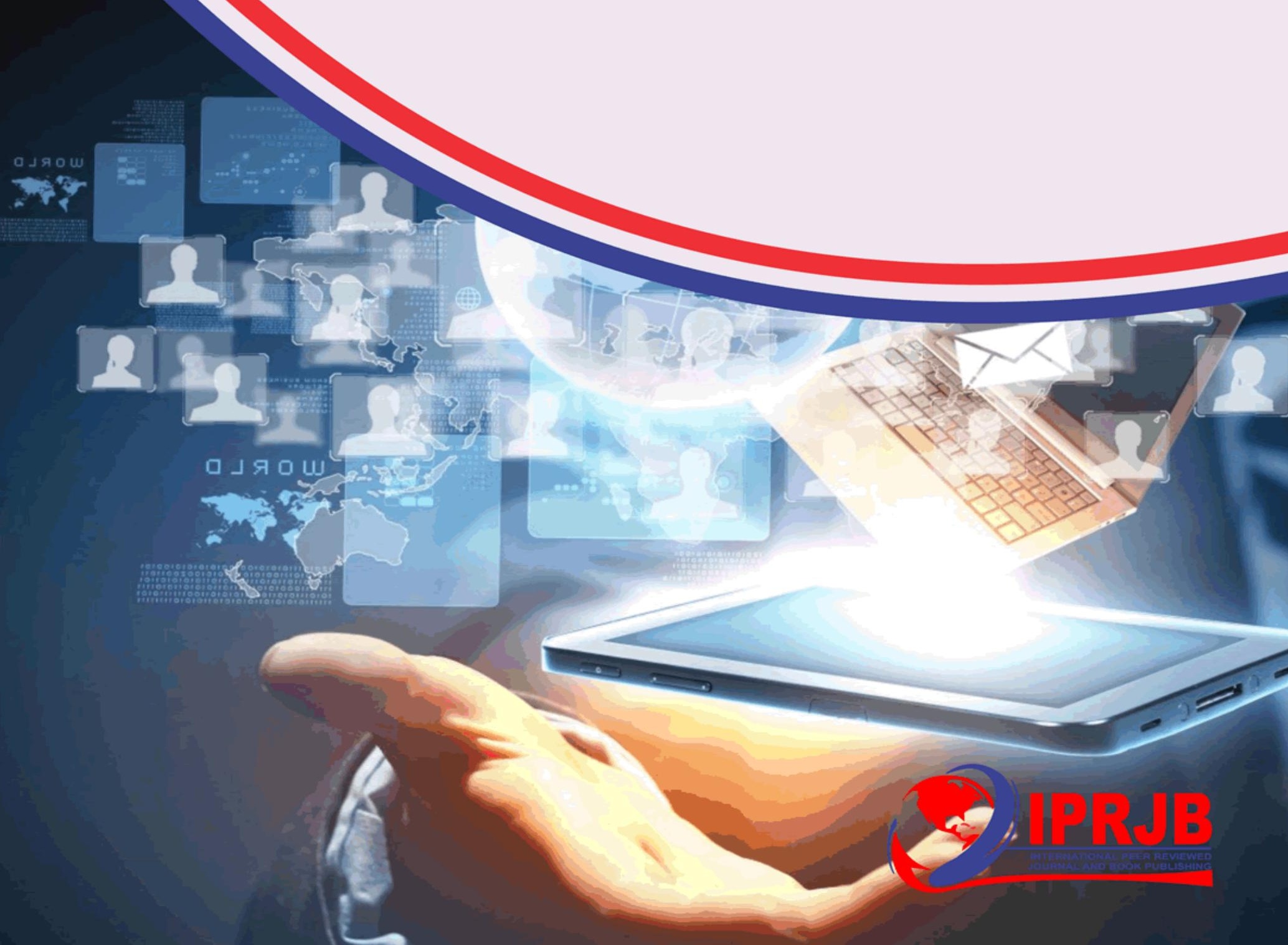




\title{
AN APPRAISAL OF VIRTUAL INTERNSHIP IN KENYA: EXPERIENCES AND PERCEPTIONS DURING COVID-19 PANDEMIC.
}

\author{
Olayo Julius Ochieng PhD, CHRP-K \\ A Certified Human Resource Professional and Lawyer \\ $\&$ \\ Lewis Waithaka Kamau: Governance Expert
}

\begin{abstract}
Purpose: This paper sought to discuss the impact of COVID-19 on Virtual internship. It explores the interns experience and perceptionon virtual internship that was accelerated by the outbreak of COVID-19.

Methodology: The study adopted a cross-sectional study on interns in different companies in Kenya. The study used both close-ended and open-ended online questionnaires to collect data from 161 interns about their experience and perception of switching to virtual internship. The data analyzed quantitatively and qualitatively.

Results: Internship programs were interrupted by COVID-19 pandemic greatly. There was low number of interns in organizations, and management made changes on the scope and intake of interns. Among the changes made by organization was the shift from traditional internship to virtual internship. The virtual interns reported great satisfaction. They reported gaining by learning technical skills and soft skills for remote work.

Unique contribution to theory, practice and policy: The findings of this study contribute and fill the gaps to the literature around virtual internship. The study recommends organizations to adopt policy that allow for virtual internship. The policy should, firstly, provide for orientation of interns. This will enable the interns to understand their scope of work and company culture. Secondly, the policy should clearly provide the most appropriate communication platforms e.g. zoom, WhatsApp, teams etc. Finally the policy should include a framework that will allow interns to attend departmental meetings. This will go a long way in exposing the interns to the company's work culture and reduce isolation.
\end{abstract}

Keywords: Virtual Internship, COVID-19, Internship, Perception, Experience. 


\section{BACKGROUND}

In March 2020, many countries woke up to the new reality of a health pandemic. COVID-19 had been reported to globally in almost all states. Governments imposed preventive measures aimed at curbing the spread of the virus. Workplace environment was one of the most affected areas. What is evidence is that the pandemic accelerated the need for organizations to adopt technology that allowed the shift to teleworking and studying from home. This was part of the organizations approach to support the government in the efforts of combating the spread of the virus (Park \& Jones, 2021). Nonetheless, there is very little research done on the impact of the pandemic on interns, despite internship being a common undertake in most of the courses in colleges and universities.

Internships are education programs that are focused on learning from experience(Linn et al., 2004). The intern is expected to learn and gain direct experience. They practice what they have learnt in the school. They provide appropriate real-world contexts for the future career of learners. Internships integrated into the program significantly improve the employment rates of graduates and are conducive to strengthening technical skills, developing thinking skills and promoting lifelong learning(Darling-Hammond et al., 2020).

Virtual internships are still education programs but which the interns learn while working out of work station(Jeske\& Axtell, 2014). They are internship that are support by technology particularly computers which are internet enabled. The interns work, learn and are assessed and supervised remotely. Research done on online internships is scarce and mainly found in the developed states such as United States of America, United Kingdom, France, German, Russia and China. In these countries the major sectors that allow virtually internships are those involved in technology(Publications, 2019).

In Africa, literature on virtual internship is scarce. Most countries have adopted the program following the outbreak of COVID-19. In South Africa for instance, several companies and NGOs have been advertising opportunities for virtual internship(Virtual International Internships | World Endeavors, n.d.). These companies have pointed to the potential of bringing in diversity and international experience. However, there is scarce research that has been conducted to explore virtual interns' experiences and perceptions.

\section{STATEMENT OF THE PROBLEM}

The most prevalent literature on internships has mainly concerned on its potential in equipping skills and creating employment among the youth(Sr., 2012)(Balwanz, 2012). The study only came a across Studies on perception and experience in traditional internship setting and not virtual(Muthaura et al., 2015).

In 2013, Massingill presented a paper at the $12^{\text {th }}$ International Conference on Information Technology Based Higher Education and Training(Massingill, 2013). The researcher notes that many students have indicated having done virtual internship. Thus, in the paper the scholar described the factors necessary for successful online internship collaboration between stakeholders, including the benefits and limitations of virtual internships, although the review is mainly based on secondary online data sources. Since the outbreak of covid-19, there are reports 
indicating many organizations either postponed, canceled or shifted to virtual internships(Feldman, 2021)(Park \& Jones, 2021)(Hora et al., 2021). The literature on the perceptions and experiences in internships during the health pandemic is scarce. Thus, this study seeks to identify the literature gaps and discuss the impact of COVID-19 on interns by exploring their perceptions and experience in virtual internship.

\section{METHODOLOGY}

The study adopted a cross-sectional study on interns in different companies in Kenya. The study used both close-ended and open-ended online questionnaires to collect data from 200 interns about their experience and perception. The survey used Likert-type questions on interns. The data was analyzed quantitatively and qualitatively.

After agreeing to ethical requirements and review of the proposed study, the link to online survey was shared with 25 organizations that had interns during the period. The content of the online survey (using Survey Monkey) included: frequency of communication between interns, and supervisors, involvement in departmental meetings, satisfaction on quality of supervision, whether the experience was worthy, skills developed, challenges and benefits.

Qualitative answers were transcribed and analyzed independently by the two authors using thematic analysis(Braun \& Clarke, 2006). Specifically, the inductive process included getting to know the transcriptions, coding, recoding and identifying topics related to the research questions. The topics were cross-checked, checked and agreed between the two authors. Any discrepancies were resolved amicably. Representative quotations were taken from the transcripts to illustrate the topics.

\section{RESULTS}

\section{Impact of COVID-19 on internships}

Government restrictive measures resulted in closing of none essential services. This affected many interns especially those who were not in medical fields. The existing cooperation between organizations and colleges in giving internships was disrupted greatly. They were ranked as high-risk areas and thus had to be closed down. Those who intended to do their internship abroad had to cancel due to travel restrictions. One of popular law schools in Kenya that takes their undergraduate to United Kingdom for Internship had to cancel first and later on agreed with the foreign organizations for virtual internships. With the implementation of measures to limit social distancing and modalities of working from home, activities such as field research, interaction with study participants, travel and events organized in public places in general have been suspended. The majority of interns $(69 \%)$ felt that they had not won as expected. Computer research internships were not affected. $80 \%$ of research interns said they can research online

\section{Student perceptions of e-internships}

The scope and quality of virtual communication were examined. Most online interns were happy with the virtual communication, and many online interns contributed outside of their scope. The trainees, who expressed their satisfaction, found that communication was mainly via Zoom, WhatsApp, email, teams. 
The trainees realized that the remote working regulations meant that there was less supervision and that they were not adequately exposed to the actual work environment. The trainees also found that there was a lack of timely feedback and guidance from their superiors. For those trainees who found the on-site support to be inadequate, the main reasons were: Difficulties in reaching their supervisor, inadequate communication or a discrepancy in expectations between trainee and supervisor. The conference call helped the trainees acquire technical skills. Most interns felt connected to other colleagues when they were allowed to attend departmental meetings.

\section{Satisfaction of virtual communication}

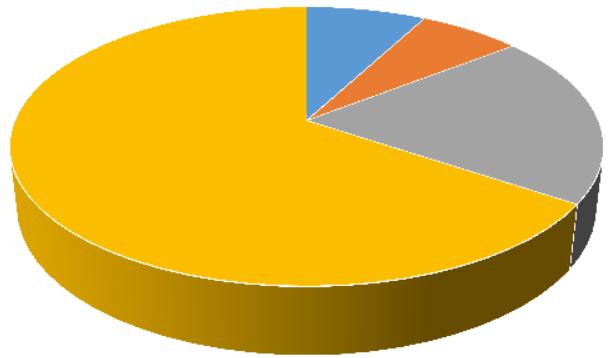

- Dissatisfied - Somewhat satisfied $\quad$ Satified $\quad$ Very satified

\section{Figure 1: Satisfaction of Virtual Communication}

Frequency of intern supervision.

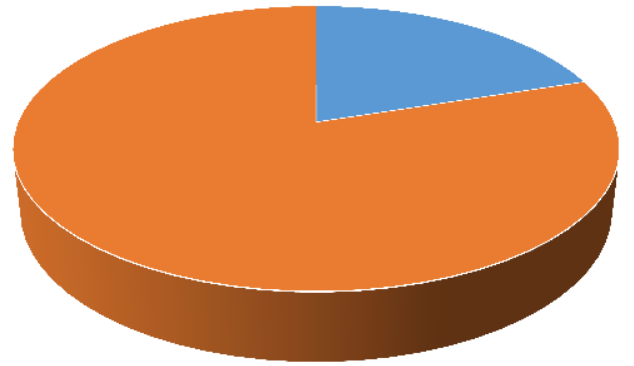

- Frequently (weekly)

- Infrequent (Ones a Month)

Figure 2: Frequency of Internship 


\section{Frequency of feedback and guidance from supervisor}

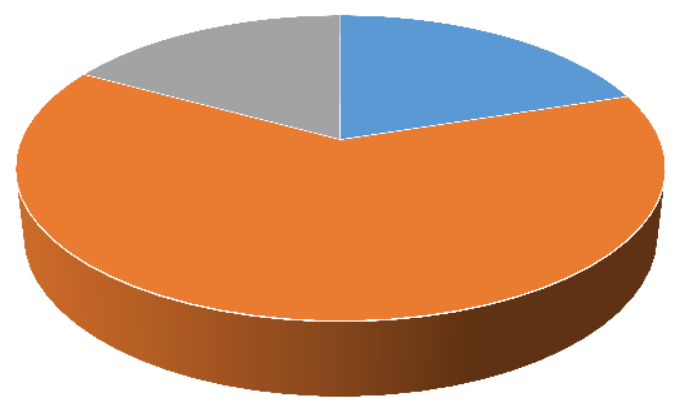

- None at all

- Infrequent (twice a month)

- Frequent (weekly)

\section{Figure 3: Frequency of Feedback and Guidance from Supervisor}

\section{Benefits and Challenges: Traditional versus Virtual Internship.}

The advantages and challenges of classic and virtual internships were recorded as follows. The skills developed from traditional internships were divided into several areas. They include technical, soft skills, critical thinking and time management.

A total of 60 out of 161 virtual trainees $(37 \%)$ stated that they had developed communication, presentation or related skills, while 90 virtual trainees $(56 \%)$ stated that teamwork, interpersonal or communication skills in verbal communication during the virtual internship had not been developed. In general, research-based interns were better able to develop technical skills, while interns with more people-centered roles were better able to develop presentation / communication skills.

\section{DISCUSSION}

This study describes the impact of COVID-19 on internships in Kenya and examines the perception of teaching and learning experiences of interns in internships during the pandemic. Overall, the internship experience was positive for the interns, as triangulated from multiple sources. The COVID-19 pandemic has caused significant disruption. Internships in many organizations in Kenya had to be canceled.

Virtual internships were rated better by interns in terms of location suitability, learning atmosphere and provision of resources than internships on site, possibly because internships had to be carried out remotely. They were also rated better by interns in termsof enjoyment. In terms of quality, the trainees valued the flexibility and independence. It has been shown that increased autonomy and the nature of remote working reduce work-related stress(Oakman et al., 2020) and that stress has a negative impact on internship satisfaction(Mensah et al., 2020). This could explain why online interns enjoyed their internship more, as common location stressors were minimized in the online internships. However, too much autonomy can be detrimental to wellbeing, although personality can affect it(Mensah et al., 2020). Remote working challenges include procrastination, poor concentration, or home distractions(Fried \& Hansson, 2013). Similar difficulties were raised by some of the participants in our study. 
The interns were contended with the quality of communication in the study. However, it crucial to note that one-on-one physical interaction at workplace plays an important part in developing socialization skills("Social Interactions and Workplace Learning," 2020). The organizations need to invest in information and communication technology that are fast and effective enough to enable and provide a good platform of communicating with interns and getting feeding. This will promote learning. Thus, there is need to invest in infrastructure that support video conferencinginstead of relying on emails and WhatsApp.

Despite frequent virtual communication, online interns felt isolated, most of them unable to experience the real work environment. According to researchers, organizations should increase their support to interns so as to curb this feeling of isolation. The support should mainly focus on ensuring that social ties between interns and the employees is strengthened. Therefore, activities that enable interns to promote social exchange, build social capital and improve learning in the virtual workplace must be deliberately structured as e-internships.

Our results largely agree with the literature on face-to-face and online internships(Jeske\& Axtell, 2016)(Investment, 2018). Online internships have similar challenges with distance learning(Roy \& Sykes, 2017) and teleworking(Jeske\& Axtell, 2014). According to Jeske and Linehan, just over half of online trainees reported developing interpersonal and communication skills, and supervised online trainees said they had developed these skills more than non-mentees(Jeske\& Linehan, 2020). In our study, there was a lower proportion of online interns who developed traditional soft skills, which indicates the need for more structured mentoring for online internships.

Despite the challenges of online internships, managers were keen to retain talent online and were open to offering part-time and / or partially virtual internships. These suggest that online internships are valued by potential employers. As teleworking increases, skills sought by employers may evolve, giving online interns an advantage over students with no prior remote work experience, as online interns would have developed essential skills for teleworking (e.g. self-management and virtual communication skills). Our results support the existing literature on the potential of online internships as a viable alternative to face-to-face internships to support student learning and their transition to work(Jeske\& Linehan, 2020).

\section{CONCLUSION AND RECOMMENDATION}

The findings of this study contribute and fill the gaps to the literature around virtual internship. The study recommends organizations to adopt policy that allow for virtual internship. The policy should, firstly, provide for orientation of interns. This will enable the interns to understand their scope of work and company culture. Secondly, the policy should clearly provide the most appropriate communication platforms e.g. zoom, WhatsApp, teams etc. Finally the policy should include a framework that will allow interns to attend departmental meetings. This will go a long way in exposing the interns to the company's work culture and reduce isolation. 
International Journal of Technology and Systems

ISSN 2518-881X (Online)

Vol.5, Issue 1, No.3, pp 28-35, 2021

WwW.iprjb.org

\section{BIBLIOGRAPHY}

Balwanz, D. (2012). Youth Skills Development, Informal Employment and the Enabling Environment in Kenya: Trends and Tensions. Journal of International Cooperation in Education, 15(2), 69-91.

Braun, V., \& Clarke, V. (2006). Using thematic analysis in psychology. Qualitative Research in Psychology, 3(2), 77-101. https://doi.org/10.1191/1478088706qp063oa

Darling-Hammond, L., Flook, L., Cook-Harvey, C., Barron, B., \& Osher, D. (2020). Implications for educational practice of the science of learning and development. Applied Developmental Science, 24(2), 97-140. https://doi.org/10.1080/10888691.2018.1537791

Feldman, E. (2021). Virtual Internships During the COVID- 19 Pandemic and Beyond. New Horizons in Adult Education and Human Resource Development, 33(2), 46-51. https://doi.org/10.1002/nha3.20314

Fried, J., \& Hansson, D. H. (2013). Remote: Office Not Required. Vermilion.

Hora, M. T., Lee, C., Chen, Z., \& Hernandez, A. (2021). Exploring Online Internships Amidst the COVID-19 Pandemic in 2020-2021: Results From a Multi-Site Case Study. Wisconsin Center for Education Research, May.

Investment, R. (2018). Journal of Work and Organizational Psychology The Nature of Relationships in e-Internships : A Matter of the Psychological Con-tract, Communication and Relational Investment. 34(1), 113-121.

Jeske, D., \& Axtell, C. (2014). e-Internships: Prevalence, characteristics and role of student perspectives. Internet Research: Electronic Networking Applications and Policy, 24. https://doi.org/10.1108/IntR-11-2012-0226

Jeske, D., \& Axtell, C. M. (2016). How to run successful e-internships: a case for organizational learning. Development and Learning in Organizations: An International Journal, 34(2), 3133. https://doi.org/10.1108/DLO-09-2015-0073

Jeske, D., \& Linehan, C. (2020). Mentoring and skill development in e-Internships. Journal of Work-Applied Management, 12(2), 245-258. https://doi.org/10.1108/JWAM-09-2019-0028

Linn, P. L., Howard, A., \& Miller, E. (2004). Handbook for Research in Cooperative Education and Internships. L. Erlbaum Publishers.

Massingill, R. (2013). Creating win-win-win experiences: When do virtual internships really work? 2013 12th International Conference on Information Technology Based Higher Education and Training (ITHET), 1-6. https://doi.org/10.1109/ITHET.2013.6671001

Mensah, C., Azila-Gbettor, E., Appietu, M., \& Agbodza, J. (2020). Internship Work-related Stress: A Comparative Study between Hospitality and Marketing Students. Journal of Hospitality \& Tourism Education, $33, \quad 14$. https://doi.org/10.1080/10963758.2020.1726769

Muthaura, P. N., Khamis, T., Ahmed, M., \& Hussain, S. R. (2015). Perceptions of the preparedness of medical graduates for internship responsibilities in district hospitals in 
Kenya: a qualitative study. BMC Medical Education, $15(1), \quad 178$. https://doi.org/10.1186/s12909-015-0463-6

Oakman, J., Kinsman, N., Stuckey, R., Graham, M., \& Weale, V. (2020). A rapid review of mental and physical health effects of working at home: how do we optimise health? BMC Public Health, 20(1), 1825. https://doi.org/10.1186/s12889-020-09875-Z

Park, M., \& Jones, T. (2021). Going Virtual: The Impact of COVID-19 on Internships in Tourism, Events, and Hospitality Education. Journal of Hospitality and Tourism Education, 33(3), 176-193. https://doi.org/10.1080/10963758.2021.1907198

Publications, U. N. (2019). Digital Economy Report 2019: Value Creation and Capture Implications for Developing Countries. UN.

Roy, J., \& Sykes, D. (2017). A Review of Internship Opportunities in Online Learning: Building a New Conceptual Framework for a Self-Regulated Internship in Hospitality. International Journal of E-Learning \& Distance Education, 32(1), 1-17.

Social interactions and workplace learning. (2020). Development and Learning in Organizations: An International Journal, 34(3), 31-33. https://doi.org/10.1108/DLO-11-2019-0275

Sr., K. R. H. (2012). Engaging the youth in Kenya: empowerment, education, and employment. International Journal of Adolescence and Youth, 17(4), 221-236. https://doi.org/10.1080/02673843.2012.657657

Virtual International Internships | World Endeavors. (n.d.). Retrieved October 9, 2021, from https://www.worldendeavors.com/virtual-international-internships 